\title{
Boron in Relation to the Fertilizer Industry
}

\author{
By J. E. Breckenridge
}

American agricul,tural Chemical Co., Carteret, N. J.

Owing to the lack of potash during the war, it was produced from many new sources, among which were materials which contained boron. In some parts of the country unusual agricultural conditions developed. Investigation revealed the fact that, in some cases, boron was present in fertilizers where injury to crops had occurred.

We find recorded experiments ${ }^{2}$ showing stimulating effects with boron in small amounts and toxic effects when larger amounts are ised.

The author's attention was called to a case in North Carolina where the farmer believed boron had injured his crop. On thorough investigation and analysis of the fertilizer used, the control officials reported boron absent. Again, another case came to the author's attention where an experienced farmer lost his crop of potatoes, but here again no boron could be found in the fertilizer used. These instances are mentioned to show that boron is not the only cause of trouble, and conclusions must not be drawn until a complete and thorough investigation has been made.

Injury to corn was first reported in Indiana in $1917 .^{3}$ Later, trouble seemed to develop in the potato crop in Maine, and the tobacco and cotton crops in the South.

The Indiana Station and the U. S. Department of Agriculture ${ }^{5}$ carried on investigations, as well as the South Carolina Experiment Station.

The conclusions as to toxic limits which have been reached have been rather indefinite. The toxic effect of boron is dependent upon how the fertilizer or fertilizer material is applied, whether broadcasted or applied in the row, and whether or not there is a good rainfall soon after planting.

A series of experiments was conducted in the greenhouse under the writer's direction, with potatoes, beans, and corn.

\section{POTATOES}

A 4-8-4 fertilizer was made in the laboratory. The government quantitative method showed 0.01 per cent borax and the qualitative method showed less than 0.01 per cent. ${ }^{6}$ The fertilizer was used at a rate of $2000 \mathrm{lbs}$. per acre, in each pot, and spread out as evenly as possible, placing it approximately 2 to $3 \mathrm{in.}$ under the seed.

Ten pots were used and the quantity of borax was as follows:

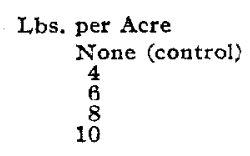

1 Presented before the Fertilizer Division at the 60th Meeting of the American Chemical Society, Chicago, Ill., September 6 to 10,1920 .

2 Brenchley, "Inorganic Plant Poisons and Stimulants," University Press, Cambridge.

- Purdue University, Bulletin 215

- Bulletin 239.

- Circular 84.

- Borax, whenever stated quantitatively, means anhydrous borax.
Good root growth was observed in the control pots and in the pots receiving 4 and $6 \mathrm{lbs}$. of borax per acre. The 8- and 10-1b. borax applications showed that the roots kept away from the fertilizer layer and developed near the surface of the soil.

The potato plants did not suffer very much, but this fact was probably due to the favorable condition which could not readily be duplicated in the field.

\section{BEANS}

Three treatments were made, using 4-8-4 fertilizer alone and with borax in the following quantities:

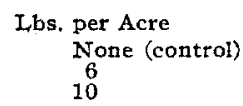

In this case a marked injurious effect was early noticeable on the plants in borax-containing pots. The control plants grew very rapidly and the leaves were of a dark green, healthy appearance. The others showed the characteristic "gilt-edge" effect of borax; the leaves soon became spotted with yellow, which spread, and the leaves later dropped off. Growth, in both cases, as compared to that of the control, was stunted. The roots of the plants showed the effect of the borax, the control plants having all roots at the seed and going down into the fertilizer. The plants in the 6-1b. per acre application had poor seed roots and had a few at the surface.

The beans showed an even more marked recovery than in the case of potatoes. New leaves forming had a healthier appearance and were not so badly spotted.

\section{$\operatorname{CORN}$}

The fertilizer used was $2-8-2,2000 \mathrm{lbs}$. to the acre, and contained less than 0.01 per cent borax. Three treatments were made:

$$
\begin{aligned}
& \text { Ibs. per Acre } \\
& \text { None (control) } \\
& 6 \\
& 10
\end{aligned}
$$

The plants grew very slowly, and for about 3 wks. the tips of the plants having 6 and $10 \mathrm{lbs}$. of borax per acre became dry, and the edges of the leaves were slightly bleached. The plants partially recovered, however, and began to grow rapidly. The plants having no borax showed good seed root formation; the $6 \mathrm{lbs}$. of borax per acre, less seed roots and more surface roots; and the $10 \mathrm{lbs}$. borax per acre, still less seed roots and more surface roots.

\section{CONCIUSIONS FROM THE POT EXPERIMENTS}

1-From the experiments it is evident that certain percentages of borax are detrimental to plant growth, but under favorable conditions such as optimum moisture, good drainage, etc., rapid recovery is noticeable.

2-Corn and beans showed borax poisoning with $6 \mathrm{lbs}$. of borax per acre, and $10 \mathrm{lbs}$. per acre showed decided harmful results.

3-Potatoes showed no harmful effects, but rather stimulating, when 4 lbs. borax and even 6 lbs. borax 
were used; 8 lbs. and 10 lbs. borax seemed to cause less root formation at the seed and more surface roots.

4-With optimum moisture plants seem to recover somewhat from the toxic effect of borax when used $6 \mathrm{lbs}$. per acre, but in short seasons the recovery would be too late for good crop results.

5-The fact that the fertilizer having more than 6 1bs. of borax to the acre prevented seed roots and the root system was largely near the surface, would result in the plants being stunted and probably dying in a dry season.

METHODS FOR DETERMINATION OF BORON

Much work has been done on the distillation method and the government method, both qualitative and quantitative, for determining boron. ${ }^{1}$

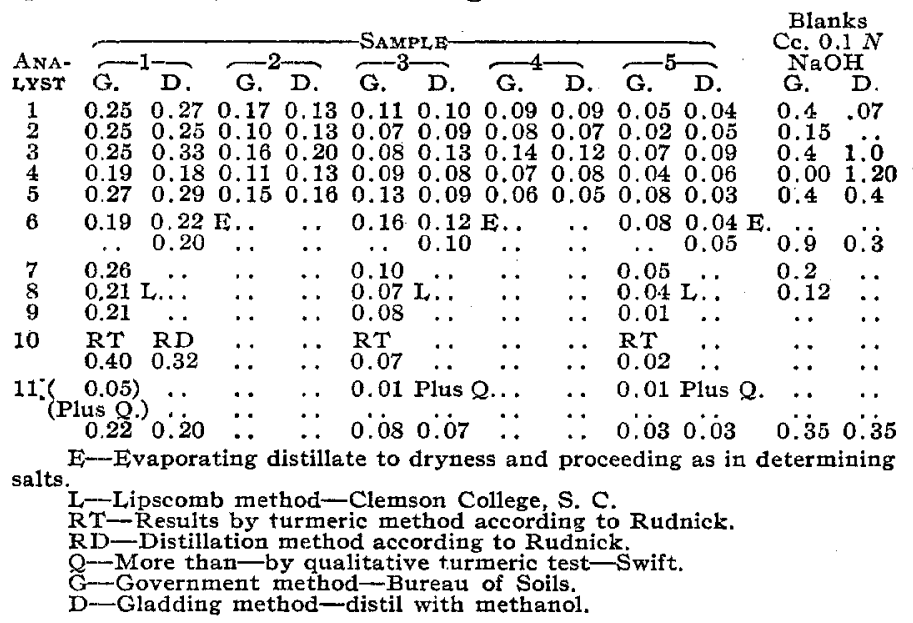

Other methods have been suggested, but are, as a rule, modifications of these two. Jones and Anderson ${ }^{1}$ of the Vermont Station have suggested a modification which is accurate and speedy. The South Carolina Experiment Station has proposed a method worked out by Lipscomb, Inman and Watkins. ${ }^{2}$

Five samples of varying percentages of borax were prepared by the writer and analyzed by five different chemists, and three of the samples were analyzed by eleven different chemists. The results are given in the accompanying table.

The borax content in Sample 1 was 0.25 per cent, and in Sample 5 less than 0.01 per cent. The other samples were:

$$
\begin{aligned}
& \text { Sample 2-0.5 No. } 1 \text { and } 0.5 \text { No. } 5 \\
& \text { Sample } 4-0.25 \text { No. } 1 \text { and } 0.75 \text { No. } 5 \\
& \text { Sample } 3-0.33 \text { No. } 1 \text { and } 0.86 \text { No. } 5
\end{aligned}
$$

Since this work has been done everyone has had more experience with the borax determinations, and the results as listed under Sample 5, which show from 0.01 up to 0.08 per cent by the government method, have been reduced to 0.01 per cent and less.

\section{CONCLUSIONS}

The gowernment method gives accurate results when carefully carried out, but time may be saved by using the Jones and Anderson modification.

All reagents must be free from carbonate.

Separation of the phosphates must be complete and no precipitate should form on standing after the final titration, which point is noted in the government method.

Results should be confirmed by the qualitative test.

\section{Determination of Chlorides in Petroleum ${ }^{2}$}

\section{By Ralph R. Matthews}

\section{Roxana Petroleum Corporation, Wood River, Illinois}

In order to determine the corrosiveness of water in petroleum; and the amount of soluble salts which may be crystallized and precipitated when the oil is distilled, a determination of chlorides in the water is generally necessary. Some light petroleums easily give up this water, and a sample can be obtained and readily titrated. There are oils, however, which do not become entirely anhydrous no matter how long they are allowed to settle, though they may eventually reach a point where there is 0.2 to 0.4 per cent of water and sediment. For such oils the method described below has been evolved so that a determination of the chlorides may be easily possible. Various other methods than the one shown have also been tried, but have failed to give concordant results.

\section{OUTIINE OF METHOD}

The sample of oil is thoroughly mixed by shaking the can, or other receptacle, in which it has been received, so that whatever salt water is present may be uniformly distributed in the oil, and $500 \mathrm{cc}$. are carefully measured into a 500-cc. graduated cylinder. The oil is then drained into a 2000-cc. graduated, glassstoppered cylinder, and $125 \mathrm{cc}$. of acetone are mea-

1 Am. Fertilizer, March 13, 1920.

2 Received January 20, 1921. sured in the same 500-cc. cylinder. (The U.S. P. grade of acetone may be used, but it must be tested to be sure no chlorides are present.) After the acetone has been added to the oil in the 2000-cc. cylinder, the two are thoroughly mixed by shaking for approximately 3 min. The action of the acetone appears to be twofold, to reduce the viscosity of the oil, and to take up and collect the salt water. The total volume is now brought up to $2000 \mathrm{cc}$. with $1375 \mathrm{cc}$. of distilled water, which is also measured in the 500-cc. cylinder, thus thoroughly cleaning out all chlorides which may have been left in the cylinder. The distilled water, oil, and acetone should be completely mixed for approximately 5 min. Care must be taken in shaking, since too violent an agitation has a tendency to produce a semi-emulsion which will settle out quite slowly. This is especially true of oil which contains much paraffin, and extreme agitation has not been found necessary for complete extraction of the acetone and salt water. The contents of the cylinder are allowed to settle until approximately $500 \mathrm{cc}$. of the water and acetone have settled out. About $400 \mathrm{cc}$. of the acetone-water mixture are next drawn off with a glass siphon. If a lit-

1 Am. Fertilizer, April 10, 1920.

2 Ibid., February 28, 1920. 